\title{
Inferno, disruption, concern, sense of community, teamwork, tears: reflections by renal healthcare team members on the front lines of the COVID-19 pandemic
}

\author{
Simona Zerbi ${ }^{1} \cdot$ Barbara Resmini $^{1} \cdot$ Maurizio Merlino ${ }^{1}$ - Carmen Licciardello ${ }^{1}$. Roberta Aloardi ${ }^{1}$ Daniela Palmetti ${ }^{1}$. \\ Laura Danelli
}

Published online: 4 January 2021

(c) Italian Society of Nephrology 2021

"Do not judge me by my success, judge me by how many times I fell down and got back up again",

(Nelson Mandela)

\section{Introduction}

Since December 2019, an outbreak of a new coronavirus disease (Covid-19), caused by severe acute respiratory syndrome coronavirus 2 (SARS-CoV-2), has grown into a global pandemic [1]. Its appearance in Italy officially dates back to February 21 st. The deadly coronavirus swept through Bergamo city and its province [2], claiming thousands of lives and putting our hospital under strain. Predictions were surpassed by the events and the magnitude of the pandemic hit us like a tidal wave. Elective surgeries were postponed and outpatient consultations were suspended. Most doctors, nurses and nurse's aides had to leave their specializations to take care of Covid-19 patients. Everyone was at risk: the doctor and the nurse, the nurse's aide and the cleaning crew. The fear of infecting our families intensified our suffering and isolation. Panic was growing and, at that moment, just being able to breathe well was felt as a blessing.

With this in mind, we would like to share a collection of thoughts about the experience of our nurses, nurse's aides and psychologists during the first surge of the pandemic, from February to May 2020. Most reflections were collected during the past summer, through moving talks that took place in the same rooms in which we had walked through

Simona Zerbi

simona.zerbi@tiscali.it

1 Nephrology and Dialysis Unit, Treviglio Hospital, ASST Bergamo Ovest, 24047, piazza Ospedale 1, Treviglio, Italy

2 Psychology Unit, Treviglio Hospital, ASST Bergamo Ovest, Treviglio, Italy hell. Everything around us was quiet, but the wheezing, hissing sounds of the ventilators somewhere in the background came back at times while we gradually drifted back to that timeless realm (Fig. 1).

\section{Inferno}

I was moved from my Renal Unit to the Covid ward overnight. Everything was unreal. A sea of infected patients arrived in a mere few hours, most of them quickly worsened and died. It was hell. Nobody talked, fear hovered over all of us. Every single day I arrived at work after a lonely car ride, donned my protective equipment and entered a paradoxical world with no idea of what was going to happen. We worked gruelling shifts. Patients were alone and stunned. The beckoning of their frightened eyes was ever-present; looked upon by patients, we watched them searching for a nod of support from us, as if to say 'it will be ok'. Who knows, I hope I was able to give them a bit of serenity, despite going through one of the worst periods in my life: I looked at them and thought of my own daughter who was in isolation with respiratory distress due to Covid-19.

But it wasn't all bad. I will always cherish the memory of the encounter between two spouses. The husband had been hospitalized weeks before due to a severe case of Covid-19. His wife came to the hospital on the day of his birthday carrying a package. We arranged to let her say hello to him from afar. It was unforgettable: he immediately recognized her and waved his arms at her with shining eyes! They were married for 52 years, Covid-19 kept them apart.

(Barbara Resmini, Nurse's Aide) 


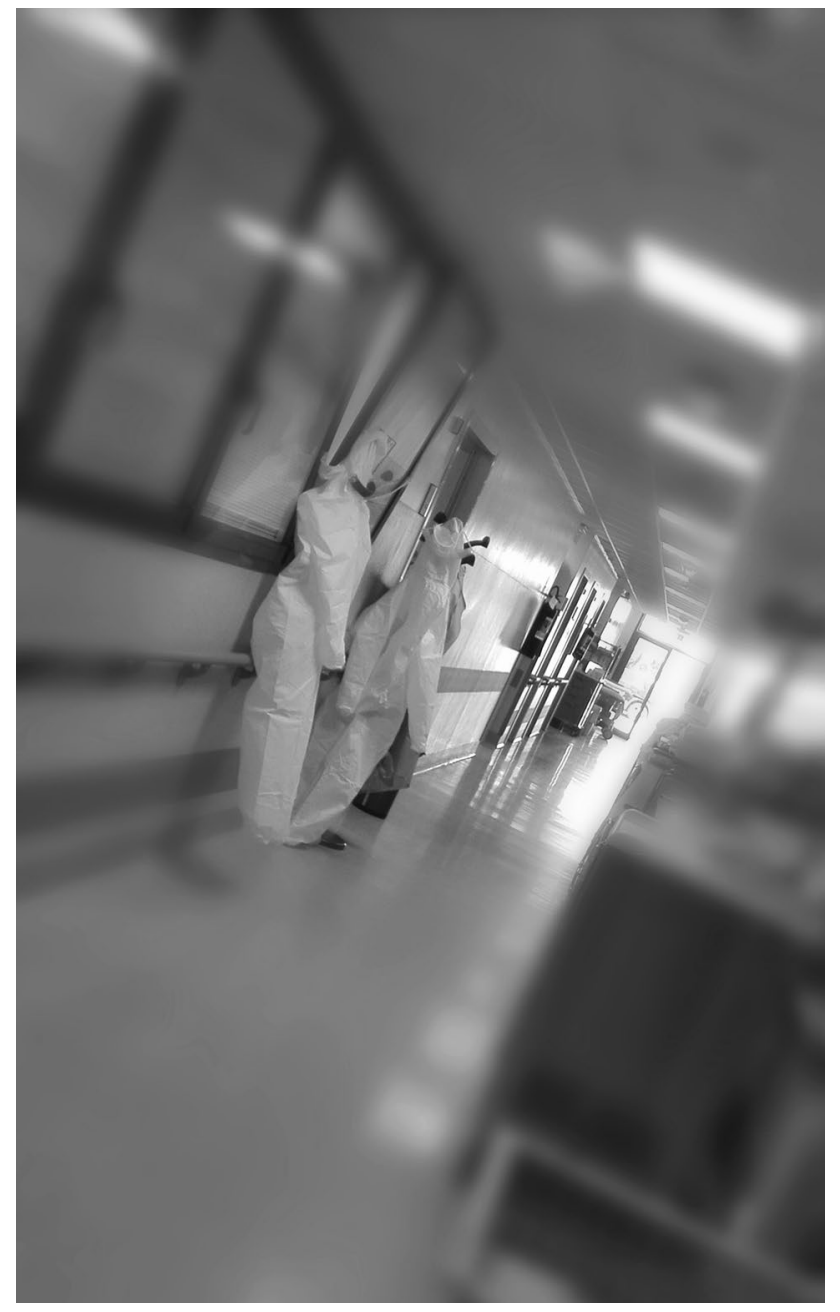

Fig. 1 Timeless realm. Courtesy of Simona Zerbi

\section{Disruption}

Everything changed on the night of February 24th during my first shift in the new Covid ward, where I had been moved from the Renal Unit. We had to completely revisit all our procedures in order to manage a scenario so severe that we could not even begin to imagine how it would play out. It was a shocking and hectic time in which we developed the utmost spirit of collaboration. No doubt, I spent the worst moments in the first half of March: in the hospital, in addition to fighting against Covid-19, we had to ration protective equipment, and at home, I tried to avoid letting all my anger, bitterness and anguish weigh on my family. While travelling to work before the lockdown, I was angry about the large number of people wandering about and I wondered how many patients would still have been alive upon my arrival. I felt mocked in hearing them call me 'the hero'. Then I came here and the ritual of 'dressing' began: I felt like a medieval knight who was preparing for battle knowing there was very little chance of winning, but ready to do his best, even though a happy ending never came. I enhanced the empathic relationship with patients through our eyes, and attempted to defuse and compensate for the absence of their relatives as much as was allowed. The tension eased a little after a shower in the locker room at the end of the shift. We exchanged a few jokes and shy laughs. It became our little ritual to regain strength for the days to come.

(Maurizio Merlino, Nurse)

\section{Concern}

I felt the seriousness of the problem when I was moved back to the Hemodialysis Unit from the Endoscopy Unit. I found a different world. I felt fear and a sensation of unreality. I had never seen anything like it in my 63 years of life. Putting on our protective clothing was, and still is, tragic, sometimes we do not even recognize each other. In the Covid-free section, my protective equipment and the abolition of the coffeebreak put some distance between the patients and me. It was odd not being constantly called, 'Carmen, when are you going to bring us our tea? Carmen, when are you coming by with the breadsticks? Carmen, the coffee is cold!', and answering in a good-natured tone: 'Stop pestering me!'. I missed those little things in life so much. Meanwhile, I had no access to the Covid section and watched patients from afar. A few of them worsened fast, were transferred to the Sub-Intensive care Unit and never came back. In Dialysis we had shared daily life, joys and anxieties for years. Losing them was painful. I was especially struck by a young woman: she was so happy to have me back in Dialysis and then she died within a few hours the next day. It was the most unforeseen and sorrowful moment.

To see families devastated by unexpected deaths made me aware that you can lose everything in no time. Now I just live for today without expectations for the future. And I feel much better than before.

(Carmen Licciardello, Nurse's Aide)

\section{Sense of community}

Following a few quick messages, Stefania, Maura, Daniela and I met on a Sunday morning to revise paths in the Dialysis Unit. In about three hours we moved wardrobes, carts and materials, creating filter areas and new access routes to reduce the risk of contagion [3]. Then it all blew up. I got scared. I felt confident only inside my protective equipment and strongly wished to put it on, even though it was exhausting to wear for hours. 
I felt so much regret for patients. Sometimes I think about how they died and how quickly it happened. We tried to hide our anguish but they felt it anyway. While leaving this room, some of them whispered "I know I'm going to die, thank you for everything". We had treated them for years and suddenly our relationship had become more loving. We had no weapons to fight the infection with, and there was so much displeasure for the end they were going to meet. I felt powerless. I tried, in my own small way, to be around them and ask (for that extra thing); when the shortness of breath prevented them from talking, I merely made them feel my closeness. At home I gave in to tears. I realized that the most valuable things I have are my family and the staff who shared this tragedy with me. A huge community spirit grew. Now there is an unbreakable bond between me and some of my colleagues.

(Roberta Aloardi, Nurse)

\section{Teamwork}

There is a before and an after. I identify the switch-over with the Sunday we met in the Dialysis Unit to modify the access routes. Then it was all a crescendo: positive swabs, infected patients, isolation. During the lockdown my trip from home to work took me across a post-apocalyptic landscape: a beautiful spring season had arrived that brought with it an unreal silence and not a soul to be seen. I wondered how nature could be so beautiful in such a tragic moment. Getting dressed was a torment, but provided me with great confidence: I have never been afraid of getting sick. Conversely, I was scared of infecting my family, which was doing its utmost to take care of me and draw my attention away from the pandemic. The emotional bond with patients became deeper: I saw them becoming afraid of getting infected, looking at their companions getting worse, greeting them for the last time before they died, and staring at their empty beds. I still remember their eyes wide open.

The pandemic exposed people: it forced us to wear masks, but took away our costumes. We finally knew the value or the smallness of the people working alongside us. I have become categorical and no longer tolerate those who pretend not to see or who deny the gravity of the pandemic. Having shared dramatic moments has created a huge connection with some colleagues, and we no longer need to talk to be able to understand one another.

(Daniela Palmetti, Nurse)

\section{Tears}

I cry, of course I cry. I cry in my car while I drive home from work, reviewing the day and thinking about the patients I've met and their most diverse requests. No one complains about the food 'that is not the same as at home' any more, nobody grumbles about the hospital bed or their neighbour's snoring, they ask what they are suffering from and if they have been infected by the virus, they smile and say that they could not have chosen a worse time to come to the hospital. Then there are the exhausted colleagues, with their dread. And yes, the virus scares us too; we are worried about spreading it to those who are waiting for us at home in the evening and understand with great patience that we cannot quit, we are terrified of spreading it to the frailest ones.

Sure, it is scary. Sometimes you would like to do more, but you can't. I've heard physicians at the end of the shift before starting self-isolation say that they wouldn't have wanted to go and leave us alone. I've listened to them say 'let's hope we can weather this storm together without losing pieces along the way'. I've heard nurses say 'I haven't done that for 20 years, but I'm here if you need me'. I've seen nurse's aides work gruelling shifts and give up seeing their grandchildren for weeks. That is why I cry. Because if I did not, I could not come back to work the next day, put on my best smile and start over again listening to all of this. And this is my only role, the only thing I am able to do and I want to keep doing it!

(Laura Danelli, Psychologist)

And now, we are at the tipping point of a second, even bigger wave; cases are surging mainly in other provinces and our hospital is supporting them. Our Renal ward was the first one to be transformed back into a Covid Unit about one month ago, followed by most of the others in the ensuing days. Hospital rooms and operating areas for intubation were set up, C-PAP and monitors were prepared, and body bags were stored. A surreal silence and the terror of facing uncertainty again prevailed throughout the whole time. The greatest pain is speechless. What we saw during the first wave of the pandemic left our feelings broken, we know it will be harder than the first time because now we know what to expect when we go to work. Despite the trauma we went through, we are ready to do our duty again. And we know our team will keep each other going, as we did before.

Acknowledgements The author is especially grateful to Barbara Resmini, Maurizio Merlino, Carmen Licciardello, Roberta Aloardi, Daniela Palmetti and Laura Danelli for having shared their experiences. In deep appreciation, the author also would like to thank all the nurses and nurse's aides of the Nephrology and Dialysis Centres of Treviglio Hospital and Romano di Lombardia Hospital for their invaluable effort during the pandemic.

Funding No funding was received for this editorial.

\section{Compliance with ethical standards}

Conflict of interest The author declares that there is no conflict of interest. 
Ethical approval This article does not contain any studies with human participants or animals performed by any of the authors.

\section{References}

1. Mahase E (2020) Covid-19 WHO declares pandemic because of "alarming levels" of spread, severity, and inaction. BMJ 368:m1036. https://doi.org/10.1136/bmj.m1036

2. Dipartimento Protezione Civile (2020) http://opendatadpc.maps. arcgis.com/apps/opsdashboard/index.html\#/b0c68bce2cce478 eaac82fe38d4138b1_Accessed 15 Mar 2020
3. Committee on Guidance for Establishing Crisis Standards of Care for Use in Disaster Situations (2012) Institute of Medicine: crisis standards of care: a systems framework for catastrophic disaster response. National Academies Press, Washington, DC

Publisher's Note Springer Nature remains neutral with regard to jurisdictional claims in published maps and institutional affiliations. 